\title{
PENGARUH LAMAZE EXERCISE TERHADAP SKALA NYERI MENSTRUASI (DYSMENORRHOEA) PADA REMAJA PUTRI DI SMA BUDI MULIA JAKARTA
}

\author{
Veronica Yeni Rahmawati ${ }^{1}$
}

\begin{abstract}
Menstrual pain present as cramps (ranging from mild to severe), which may disturb daily activities. Lamaze exercise is non pharmacological method which use breathing relaxation. This research was to analyze Lamaze exercise to reduction of menstrual pain. This study used pra experimental pre post test design. The population was the students with menstrual pain at Budi Mulia Senior High School Jakarta. The sampling technique was purposive sampling. Thirty one students participated in this study. The independent variable was Lamaze exercise and the dependent variable was menstrual pain. Instrument which used to measure pain was Visual Analog Numeric Rating Scale. Data were analyzed with Wilcoxon Signed Rank Test with significance $\alpha \leq 0.005$. The result showed that Lamaze exercise decreasd menstrual pain. The result of statistical test showed significance level $p=0.000$ and the deviation between pre and post mean is 2.32, which means that there was decreasing menstrual pain in student in pre test and post test. It can be concluded that Lamaze exercise can influence menstrual pain in decrease respondent of the research. Lamaze exercise can provide a relaxing effect. Further experiment with different respondent characteristic to obtain more wide range of result.
\end{abstract}

Keywords: menstrual pain, Lamaze, relaxing effect, non pharmacological method

\section{PENDAHULUAN}

Nyeri menstruasi (dysmenorrhoea) merupakan salah satu masalah ginekologi yang paling umum dialami remaja putri dan wanita produktif (Wiknjosastro, 2007). Nyeri menstruasi ini menyebabkan remaja mengalami gangguan dalam beraktivitas. Sebagian besar dari mereka sulit berkonsentrasi belajar saat nyeri muncul, sehingga banyak remaja ingin meninggalkan pelajaran saat proses belajarmengajar berlangsung, bahkan mereka memilih untuk beristirahat di rumah atau tidak masuk sekolah (Hart, 2004). Hasil kuesioner yang dilakukan peneliti terhadap remaja putri di SMA Budi Mulia Jakarta, dari 147 remaja putri terdapat 37 remaja (22\%) yang mengkonsumsi obat setiap bulan untuk mengatasi nyeri menstruasinya.

Masa remaja merupakan periode transisi dari masa anak ke masa dewasa yang ditandai dengan percepatan perkembangan fisik, mental, emosional dan sosial. Dampak dari nyeri menstruasi yang kerap menyertai remaja antara lain: gangguan dalam bersosialisasi dengan teman sebaya, perasaan malas bergerak, badan lemas, mudah capek, ingin makan terus, emosi jadi lebih labil, sensitif, mudah marah (Haditomo, 2002). Remaja mengatasi rasa nyeri tersebut dengan istirahat dan meninggalkan pelajaran atau kegiatannya seharihari untuk beberapa jam (Llewellyn, 2002). Menurut Roger (2010), nyeri menstruasi dapat diatasi dengan manajemen nyeri yaitu suatu tindakan atau strategi khusus untuk menghilangkan nyeri, antara lain dengan tindakan farmakologi (asam mefenamat) dan non farmakologi. Tindakan non farmakologi mempunyai banyak keunggulan yaitu sangat mudah diaplikasikan 
dan tidak membutuhkan biaya yang besar.

Penyebab utama dari nyeri menstruasi adalah terjadinya hiperkontraktilitas uterus, hal ini juga yang dirasakan oleh ibu inpartu kala I fase aktif (Prawirohardjo, 2005). Penelitian Amis (2009), Lamaze exercise terbukti mampu menurunkan nyeri pada ibu inpartu kala I fase aktif, namun pengaruh Lamaze exercise terhadap skala nyeri menstruasi (dysmenorrhoea) belum dapat dijelaskan. Keluhan nyeri menstruasi biasanya baru timbul 2-3 tahun sesudah menarce. Biasanya gangguan ini mencapai puncaknya pada umur 17-25 tahun (Jones, 2005). Data awal yang didapatkan peneliti di Kelurahan Mangga Dua Selatan pada tanggal 26 November 2015, dari 167 remaja putri ditemukan 147 remaja putri (88\%) menyatakan mengalami nyeri saat menstruasi. Sebagian besar rasa nyeri berlokasi di pinggang, sedangkan $5.7 \%$ mengalami sakit kepala. Sebanyak $22 \%$ remaja putri bisa tetap mengikuti pelajaran dengan mengatasi nyerinya menggunakan obat-obatan penghilang rasa sakit. Data dari absensi $15 \%$ remaja putri dari September 2014 sampai dengan September 2015 tidak masuk sekolah karena mengalami nyeri menstruasi. Peneliti mendapatkan informasi dari penanggung jawab UKS SMA Budi Mulia Jakarta, penanganan yang dilakukan terhadap remaja putri yang mengalami nyeri menstruasi adalah dengan memberi terapi farmakologis (asam mefenamat). Penelitian tentang nyeri menstruasi oleh Novita (2009), di SMA Negeri 1 Sidoarjo menyatakan dari 173 siswi ditemukan 133 siswi (75\%) mengalami nyeri menstruasi dari derajat ringan sampai berat $(74.1 \%)$ dan sebanyak 30\% siswi tidak masuk sekolah karena mengalami nyeri menstruasi.
Lamaze exercise merupakan teknik relaksasi nafas yang dapat dijadikan sebagai salah satu kompetensi nonfarmakologis dalam upaya menurunkan nyeri menstruasi pada remaja. Kelebihan dari Lamaze exercise dibanding terapi non farmakologi lain adalah mudah diaplikasikan sewaktu-waktu saat nyeri menstruasi timbul (Michelle, 2011). Lamaze exercise mengaktifkan sistem saraf parasimpatis (Fraser, 2000). Sistem saraf parasimpatik membuat pembuluh darah mengalami vasodilatasi, sehingga sirkulasi peredaran darah meningkat. Adanya sirkulasi yang lancar ini juga berpengaruh pada otot uterus. Otot uterus akan relaks dan mengakibatkan oksigen otot meningkat. Lamaze exercise yang dilakukan pada siswi saat nyeri menstruasi akan memberikan persepsi positif yang kemudian diterima oleh korteks cerebri. Hal ini mempengaruhi proses fisiologis dalam tubuh melalui sistem HPA axis. Jalur HPA axis, hipothalamus melepas Corticotrophin Releasing Factor (CRF). Selanjutnya CRF merangsang kelenjar pituitary untuk mempengaruhi medulla adrenal dalam meningkatkan produksi proopioidmelanocortin (POMC) sehingga produksi enkephalin juga meningkat. Kelenjar pituitary juga menghasilkan $\beta$-endorphin sebagai neurotransmitter yang dapat mempengaruhi suasana hati menjadi rileks dan sebagai opiat untuk mengurangi rasa sakit. Peningkatan $\beta$-endorphin dan enkephalin menyebabkan tubuh menjadi rileks sehingga persepsi nyeri berkurang dan intensitas nyeri berkurang (Ganong, 2000).

\section{TUJUAN PENELITIAN}

Tujuan penelitian ini adalah untuk menganalisis pengaruh Lamaze exercise terhadap skala nyeri menstruasi (dysmenorrhoea). 
METODE/DESAIN PENELITIAN

Dalam penelitian ini desain yang digunakan adalah pra eksperimental (one group pre-post test design) yaitu kelompok subyek yang memenuhi kriteria inklusi dari peneliti diobservasi sebelum dilakukan intervensi, kemudian diobservasi ulang setelah dilakukan intervensi (Nursalam, 2008).

\section{POPULASI, SAMPEL, DAN TEKNIK SAMPLING}

Populasi pada penelitian ini adalah remaja putri di SMA Budi Mulia Jakarta yang mengalami nyeri menstruasi berjumlah 147 remaja putri. Sampel dalam penelitian ini adalah penderita nyeri menstruasi di SMA Budi Mulia Jakarta yang memenuhi kriteria inklusi. Kriteria inklusi pada penelitian ini adalah remaja putri yang menarce umur 1415 tahun, mengalami nyeri menstruasi tingkat ringan dan sedang, belum mendapat terapi anti nyeri (farmakologis dan non farmakologis) serta bersedia menjadi responden. Adapun kriteria eksklusinya adalah remaja putri yang mengalami dysmenorrhoea sekunder atau dengan keluhan yang lain (misalnya appendicitis, polip endometrium, kista ovarium).

Pada penelitian ini, tehnik yang digunakan adalah Non Probability Sampling (Purposive Sampling) yaitu dengan memilih sampel yang dikehendaki peneliti sesuai tujuan atau masalah penelitian (Nursalam, 2008). Pengumpulan data skala nyeri menggunakan Visual Analog Numeric Rating Scale yang merupakan modifikasi skala nyeri Bourbanais menurut Smeltzer dan Bare (Acello, 2002) yang terdiri dari rentang skor 0-10. Skor-skor ini mewakili tingkat intensitas nyeri yang dilaporkan oleh responden dimana bila tidak nyeri (skor 0), nyeri ringan (skor 1-3), nyeri sedang (skor 4-6), nyeri berat (skor 7-9), sangat nyeri (10).
Penelitian dilakukan di SMA Budi Mulia Jakarta dengan pertimbangan belum pernah diberikan penelitian seperti ini sebelumnya. Penelitian ini dilaksanakan selama 1 bulan. Kuesioner Visual Analog Numeric Rating Scale (pre test) diberikan kepada responden secara individu sebelum diberikan intervensi. Peneliti melakukan observasi tingkat nyeri responden sebelum melakukan intervensi. Intervensi diberikan selama 8 menit sesuai dengan prosedur. Sesudah dilakukan Lamaze exercise peneliti meminta responden mengisi lembar kuesioner Visual Analog Numeric Rating Scale (post test). Peneliti melakukan observasi tingkat nyeri responden dan menuliskannya pada lembar observasi skala nyeri yang telah disiapkan. Skala data yang digunakan adalah ordinal, yaitu perubahan skala nyeri sebelum dan sesudah dilakukan intervensi Lamaze exercise dengan uji Wilcoxon Signed Rank Test. Uji ini untuk mengetahui komparatif sample yang berkorelasi dengan tingkat kemaknaan $\alpha \leq 0.05$ apabila $p \leq \alpha$ maka Ho ditolak dan hipotesis diterima. Hal ini berarti ada pengaruh Lamaze exercise terhadap skala nyeri menstruasi (dysmenorrhoea) sebelum dan sesudah intervensi.

\section{HASIL PENELITIAN}

Distribusi responden berdasarkan umur menunjukkan sebagian besar berumur 16 tahun dengan jumlah 16 responden $(52 \%)$ sedangkan responden yang berumur 18 tahun berjumlah 2 orang (6\%). Dari 31 responden, sebagian besar mengalami 1 keluhan lain yaitu pusing sebanyak 20 responden $(65 \%)$ dan 1 responden (2\%) mengalami 3 keluhan lain selain nyeri menstruasi yaitu pusing, nyeri punggung dan darah menstruasi banyak. Sebagian besar responden 
selalu merasakan nyeri menstruasi berjumlah 22 responden (71\%) dan responden yang kadang-kadang merasakan nyeri berjumlah 9 orang (29\%). Distribusi responden berdasarkan pengalaman mengatasi nyeri menstruasi yang meminum obat berjumlah 7 responden (23\%), sedangkan responden yang membiarkan saja sambil menahan nyeri berjumlah 14 responden $(45 \%)$.

Tabel 1.

Skala Nyeri Menstruasi pada Responden Sebelum dan Sesudah Dilakukan Lamaze Exercise di SMA Budi Mulia Jakarta Bulan Januari-

\begin{tabular}{lcc}
\multicolumn{3}{c}{ Februari $2016(\mathrm{~N}=16)$} \\
\hline Kategori & Pre Test & Post Test \\
\hline Tidak nyeri & 0 & 2 \\
& $0 \%$ & $6 \%$ \\
Nyeri ringan & 6 & 24 \\
& $19 \%$ & $77 \%$ \\
Nyeri sedang & 25 & 5 \\
& $81 \%$ & $17 \%$ \\
Nyeri berat & 0 & 0 \\
& $0 \%$ & $0 \%$ \\
Sangat nyeri & 0 & 0 \\
& $0 \%$ & $0 \%$
\end{tabular}

Dari table di atas menunjukkan bahwa sebelum diberikan perlakuan Lamaze exercise, sebagian besar responden mengalami nyeri sedang sebanyak 25 responden (81\%). Setelah dilakukan Lamaze exercise menunjukkan perubahan tingkat nyeri menstruasi yang dirasakan responden yaitu sebanyak 2 responden $(6 \%), 24$ responden $(77 \%)$ merasakan nyeri ringan dan 5 responden $(17 \%)$ merasakan nyeri sedang.
Tabel 2.

Pengaruh Lamaze exercise terhadap tingkat nyeri pada remaja putri di SMA Budi Mulia Jakarta sebelum dan sesudah diberikan intervensi

\begin{tabular}{|c|c|c|c|c|c|}
\hline \multirow{2}{*}{ No. } & \multicolumn{2}{|c|}{ Skala nyeri } & \multirow{2}{*}{ No. } & \multicolumn{2}{|c|}{ Skala Nyeri } \\
\hline & Pre & Post & & Pre & Post \\
\hline 1 & 6 & 2 & 17 & 3 & 4 \\
\hline 2 & 5 & 1 & 18 & 3 & 2 \\
\hline 3 & 5 & 3 & 19 & 5 & 3 \\
\hline 4 & 6 & 4 & 20 & 6 & 3 \\
\hline 5 & 5 & 3 & 21 & 3 & 2 \\
\hline 6 & 5 & 3 & 22 & 4 & 3 \\
\hline 7 & 2 & 1 & 23 & 5 & 3 \\
\hline 8 & 5 & 1 & 24 & 5 & 3 \\
\hline 9 & 6 & 4 & 25 & 4 & 1 \\
\hline 10 & 6 & 2 & 26 & 6 & 2 \\
\hline 11 & 2 & 0 & 27 & 5 & 2 \\
\hline 12 & 5 & 2 & 28 & 1 & 0 \\
\hline 13 & 6 & 4 & 29 & 5 & 2 \\
\hline 14 & 6 & 4 & 30 & 5 & 3 \\
\hline 15 & 6 & 3 & 31 & 5 & 1 \\
\hline 16 & 4 & 2 & & & \\
\hline \multicolumn{3}{|c|}{ Pre } & \multicolumn{3}{|c|}{ Post } \\
\hline \multirow{2}{*}{\multicolumn{2}{|c|}{$\begin{array}{l}\text { Mean } \\
\text { Std. } \\
\text { Deviasi }\end{array}$}} & 4.68 & \multirow{2}{*}{\multicolumn{2}{|c|}{$\begin{array}{l}\text { Std. } \\
\text { Deviasi }\end{array}$}} & 2.35 \\
\hline & & 1.35 & & & 1.14 \\
\hline
\end{tabular}

Dari tabel di atas dapat diketahui bahwa terjadi penurunan skala nyeri sebanyak 1 hingga 4 skala. Lima responden mengalami penurunan sebanyak 1 poin, 13 responden mengalami penurunan sebanyak 2 poin, 6 responden mengalami penurunan sebanyak 4 poin, dan 1 orang responden mengalami peningkatan skala sebanyak 1 poin. Hasil uji statistik menggunakan uji statistik Wilcoxon Signed Rank Test, nilai sig (2-tailed) pada intervensi Lamaze exercise nilai $p=0.000$, yang berarti $p \leq \alpha \leq 0.05$ maka $\mathrm{H}_{1}$ diterima artinya Lamaze exercise berpengaruh terhadap perubahan skala nyeri menstruasi. 


\section{PEMBAHASAN}

Skala nyeri menstruasi pada remaja putri di SMA Budi Mulia Jakarta sebelum dilakukan Lamaze exercise sebagian besar mengalami nyeri sedang. Pengukuran nyeri dilakukan dengan menggunakan Visual Analog Numeric Rating Scale yang menunjukkan rentang skala 1-10. Karakteristik nyeri sedang adalah nyeri yang menyebar di bagian perut bawah, memerlukan istirahat dan memerlukan obat penangkal nyeri serta kadang mengganggu aktivitas hidup sehari-hari (Biben, 2009). Sebagian besar responden datang ke UKS dengan menahan sakit di bagian perut bawah dan memerlukan obat penghilang nyeri, berdasarkan hasil kuesioner dan observasi responden berada pada tingkat nyeri sedang.

Responden pada penelitian ini yang mengalami nyeri menstruasi tingkat ringan dan sedang berada pada umur 16-18 tahun. Mayoritas responden yang berumur 16 tahun mengalami nyeri sedang. Apabila individu sudah pengalaman nyeri sebelumnya dapat merubah sensasi klien terhadap nyeri secara personal dengan cara mengantisipasi nyeri dibandingkan orang yang tidak mempunyai pengalaman nyeri (Brunner, 2002). Perbedaan tingkat nyeri menstruasi pada responden tersebut kemungkinan dipengaruhi oleh umur responden karena dengan umur yang lebih dewasa, maka toleransi terhadap nyeri akan lebih baik dan semakin banyak pengalaman dalam menghadapi masalah gangguan rasa nyaman (nyeri) yang dialami sehingga lebih mampu menggunakan koping yang adaptif untuk mengatasi nyeri yang dialami.

Skala nyeri menstruasi pada remaja putri di SMA Budi Mulia Jakarta setelah dilakukan Lamaze exercise, sebagian besar mengalami penurunan skala nyeri menstruasi, dari nyeri sedang menjadi nyeri ringan. Dari 31 responden terdapat 24 responden mengalami penurunan nyeri menstruasi sebanyak 3-4 poin, 6 responden mengalami kategori nyeri menstruasi yang tetap meskipun mengalami penurunan 1-2 poin, dan 1 orang responden mengalami peningkatan tingkat nyeri sebanyak 1 poin.

Menurut Roger (2010), nyeri menstruasi dapat diatasi dengan manajemen nyeri yaitu suatu tindakan atau strategi khusus untuk menghilangkan nyeri, antara lain dengan tindakan farmakologi (asam mefenamat) dan non farmakologi. Lamaze exercise merupakan salah satu gerakan latihan relaksasi nafas yang dapat digunakan untuk menurunkan nyeri menstruasi. Nyeri menstruasi yang dialami oleh sebagian besar responden dapat menurun mungkin dikarenakan teknik ini mudah untuk dilakukan tanpa ada efek samping.

Penurunan skala nyeri menstruasi sebanyak 3-4 poin hampir dialami oleh sebagian besar responden. Strategi untuk mengatasi rasa nyeri antara lain memusatkan perhatian pada titik perhatian tertentu, sehingga jalur saraf terisi oleh stimulus lain dan tidak dapat memberi respon terhadap stimulus nyeri (Bobak, 2004). Penurunan nyeri menstruasi yang dialami oleh sebagian besar responden dikarenakan responden dapat mengikuti teknik Lamaze exercise dengan baik dan benar, mereka melakukan teknik ini dengan fokus.

Kategori nyeri menstruasi yang tetap meskipun mengalami penurunan sebanyak 1-2 poin terjadi pada 6 responden, yaitu responden nomer 4, 7, 9, 13, 14, dan 18. Sebagian besar responden tetap mengalami nyeri sedang. Kelelahan mengurangi kemampuan seseorang untuk mengatasi nyeri, bahkan ikut meningkatkan intensitas nyeri yang dirasakan (Kozier, 1997). 
Responden tersebut mengalami nyeri menstruasi saat siang hari, mereka datang ke UKS dalam keadaan sudah lelah beraktivitas di dalam kelas. Hal ini yang mungkin menyebabkan tingkat nyeri yang dirasakan oleh responden tetap meskipun mengalami penurunan 1-2 poin.

Salah satu responden pada penelitian ini yaitu responden nomer 17 mengalami peningkatan skala nyeri menstruasi. Lingkungan sangat mempengaruhi tingkat respon individu terhadap nyeri, keadaan lingkungan yang tidak baik atau tidak nyaman meliputi keadaan ribut dan ramai maupun udara yang sangat dingin ataupun panas dan kelembaban akan mempengaruhi peningkatan intensitas nyeri individu ke suatu tingkat yang lebih berat (Brunner, 2002). Berkaitan dengan hal tersebut, peningkatan skala nyeri menstruasi yang dialami oleh responden mungkin disebabkan karena saat responden datang ke UKS diantar dan ditemani oleh beberapa temannya sehingga konsentrasi responden menjadi berkurang.

Dari data demografi responden berdasarkan frekuensi nyeri menstruasi, terdapat 22 responden yang selalu mengalami nyeri menstruasi dan hanya 9 responden yang kadang-kadang mengalami nyeri menstruasi setiap bulannya. Individu yang mempunyai pengalaman multipel dan berkepanjangan dengan nyeri akan lebih sedikit gelisah dan lebih toleran terhadap nyeri dibanding individu yang hanya mengalami sedikit nyeri (Smeltzer, 2002). Responden yang selalu mengalami nyeri menstruasi setiap bulannya akan lebih toleran terhadap nyeri dibandingkan dengan responden yang hanya kadang-kadang mengalami nyeri menstruasi.

Selain itu banyaknya keluhan yang dirasakan juga berpengaruh terhadap skala nyeri yang dirasakan. Dapat dilihat bahwa responden yang mengalami penurunan tingkat nyeri sebanyak 3 dan 4 skala hanya mengalami 1 keluhan saja yaitu pusing. Hal ini berbeda dengan responden yang mengalami penurunan nyeri minimal (1 skala) yang mengalami lebih dari 1 keluhan. Munculnya gejala lain yang kerap kali mengiringi nyeri menstruasi pada individu menyebabkan rasa nyeri menstruasi tetap ada bahkan memperberat rasa nyeri tersebut meskipun sudah dilakukan penanganan (Pallavi, 2010). Penurunan tingkat nyeri 1 poin tersebut kemungkinan karena lebih banyak keluhan yang dialami sehingga skala responden terhadap nyeri yang dirasakan semakin meningkat.

Jika dilihat dari pengalaman dalam mengatasi nyeri menstruasi dapat diidentifikasi bahwa mayoritas responden yang mengalami penurunan tingkat nyeri 3 dan 4 poin biasanya mengatasi nyeri dengan beristirahat/tidur. Hal ini berbeda dengan responden yang mengalami penurunan nyeri minimal (1 poin) yang biasanya mengatasi nyeri dengan dibiarkan sambil menahan rasa nyeri tersebut. Penurunan tingkat nyeri 3 dan 4 poin tersebut kemungkinan karena responden yang mengatasi nyeri menstruasi dengan beristirahat/tidur mempunyai toleransi terhadap nyeri yang lebih baik. Selain itu responden berada pada tingkat pendidikan yang sama, sehingga mereka memiliki pengetahuan yang sama tentang nyeri. Ketika mengalami nyeri menstruasi, individu menggunakan berbagai mekanisme koping untuk mencoba mengatasinya.

Setiap perempuan mempunyai teknik atau cara berbeda-beda dalam mengatasi nyeri menstruasi yang dialaminya. Seseorang yang mengalami lebih banyak keluhan lain saat menstruasi cenderung 
tetap mengalami tingkat nyeri tersebut bahkan bisa meningkat dibandingkan seseorang yang tidak mengalami keluhan lain saat menstruasi. Tiap individu memiliki tingkat nyeri menstruasi yang bervariasi. Individu yang mengalami tingkat nyeri semakin berat memerlukan teknik-teknik yang lebih khusus dalam penanggulangan nyeri menstruasi. Kelebihan dari Lamaze exercise dibanding terapi non farmakologi lain adalah bebas dari efek samping dan mudah diaplikasikan sewaktu-waktu saat nyeri menstruasi timbul. Jadi teknik Lamaze exercise bisa atau dapat digunakan untuk menurunkan tingkat nyeri menstruasi.

\section{KESIMPULAN}

Penelitian ini memberikan gambaran bahwa skala nyeri menstruasi sebagian besar remaja putri di SMA Budi Mulia Jakarta sebelum dilakukan Lamaze exercise adalah nyeri sedang. Skala nyeri menstruasi sebagian besar remaja putri di SMA Budi Mulia Jakarta setelah dilakukan Lamaze exercise mengalami penurunan sebesar 2 poin menjadi nyeri ringan. Lamaze exercise menurunkan skala nyeri menstruasi pada remaja putri di SMA Budi Mulia Jakarta. Lamaze exercise dapat meningkatkan sirkulasi peredaran darah sehingga berpengaruh pada otot uterus. Otot uterus akan relaks dan mengakibatkan oksigen otot meningkat sehingga skala nyeri menstruasi dapat berkurang.

\section{SARAN}

1. Bagi perawat dalam memberikan asuhan keperawatan pada kasus nyeri menstruasi dapat menggunakan salah satu alternatif tindakan nonfarmakologi yaitu teknik Lamaze exercise sehingga masalah gangguan rasa nyaman (nyeri) dapat teratasi.
2. Bagi sekolah (UKS) dapat memodifikasi lingkungan agar bersih, karena letak UKS yang dekat dengan kamar mandi dirasa kurang kondusif bagi siswa yang memerlukan istirahat di UKS.

3. Bagi remaja yang membaca hasil penelitian ini diharapkan menggunakan Lamaze exercise yang dapat menurunkan tingkat nyeri menstruasi, sehingga apabila mengalami nyeri menstruasi bisa diatasi dengan baik.

4. Bagi peneliti selanjutnya perlu melakukan penelitian dengan karakteristik responden yang berbeda.

\section{DAFTAR PUSTAKA}

Biben, A. 2009. Waspadai Nyeri Haid. Universitas Padjajaran, Bandung.

Bobak, Lowdermilk, Jensen. 2010. Buku Ajar Keperawatan Maternitas. Alih bahasa Maria A. Wijayarini, Peter I. Anugerah; editor edisi bahasa Indonesia Renata Komalasasri. Ed.4. EGC, Jakarta.

Braverman, P.K. dan S.J. Sondhelmer. 1997. Menstrual disorders. Pediatrics in Review. 18:17-26.

Smeltzer, S.C. dan B.G. Bare. 2008. Keperawatan Medikal Bedah. EGC, Jakarta.

Budin, Wendy C., Gross, Leon. Lothian, Judith A. Mendelson, Jeanne. 2014. Knowledge and Skills of the Lamaze Certified Childbirth Educator: Results of a Job Task Analysis. The Journal of Perinatal Education. DOI:10.1891/1058-1243.23.2.65. US National Library of Medicine National Institutes of Health

Corwin, J.G. 1997. Buku Saku Patofisiologi. Penerbit Buku Kedokteran EGC, Jakarta. 
Edmonds, K. 2007. Gynaecological Disorders of Childhood and Adolescence. Dewhurt's Textbook of Obstetrics dan Gynaecology 7th ed. Blackwell Publishing, London.

Fajaryati, N. 2012. Hubungan kebiasaan olah raga dengan disminore primer remaja putri di SMPN.2 Mirit Kebumen. http://ejournal.akbidpurworejo.ac .id/index.php/jkk4/article/view/62

Fitria. 2007. Haid Tidak Wajar dan Menopause. Pustaka Populer Obor, Jakarta.

French, Linda M.D. 2005. Dysmenorrhea. American Family Physician Michigan State University collage of human medicine. East lansing. Michigan.

Ganong, William F. 2003. Buku Ajar Fisiologi Kedokteran. Edisi 20. Penerbi Buku Kedokteran EGC, Jakarta.

Glasier, Anna. 2006. Keluarga Berencana dan Kesehatan Reproduksi. Edisi keempat. EGC, Jakarta.

Guylane, Lefebvre. 2005. Primary dysmenorrhea consensus guidelines. SOGC. Clnical Practice Guideline, 169, 11171122. Diakses tanggal 7 Agustus 2015.

Guyton, Hall. 2012. Buku Ajar Fisiologi Kedokteran. Penerbit Buku Kedokteran. EGC, Jakarta.

Haditomo, F.J. Monks, Koers, S.R. 2002. Psikologi perkembangan: pengantar dalam berbagai bagiannya. Gadjah Mada University Press, Yogyakarta.

Hamilton, Persis Mary. 2009. DasarDasar keperawatan maternitas; alih bahasa, $\mathrm{Ni}$ Luh Gede Yasmin Asih. Ed 6. EGC, Jakarta.

Hart dan Moore. 2004. Esensial Obstetri dan Ginekologi. Hipokrates, Jakarta.

Jones, Derek Liewellyn. 2005. Setiap wanita. Alih bahasa: Elisa
Carolina. PT. Delapratasa Publishing.

Kozier, B. Erb, G dan Oliveri, R. 2011. Fundamental of nursing: concept, process and practice. The Benjamin/Cummings Publishing Co. Inc, California.

Kusumawardhani, Ratih Dwi. 2010. Pengaruh Masase Aromaterapi Lavender (Lavandula Angustifolia) terhadap Skala Nyeri Menstruasi Pada Siswi SMA GIKI 2 Surabaya. PSIK FK Unair. Skripsi tidak dipublikasikan, Surabaya.

Lindgren, Maryclaire. 1999. Relaxation Techniques Improve Preterm Labour Outcomes. Women's Health Weekly.

Llewellyn. 2002. Dasar-Dasar Obstetri dan Ginekologi. Hipokrates, Jakarta.

Lyrawati, Diana. 2009. Penilaian Nyeri. Pemeriksaan-danpenilaian-nyeri.pdf. Diakses pada tanggal 8 Agustus 2015.

Lusa. 2012. Dysmenorrhea Part I. http://www.lusa.web.id/disminore dysmenorrhea-part-l/

Mansjoer, Arif. 2000. Kapita Selekta kedokteran Edisi 3 Jilid 1. Media Aeculapius. FK UI, Jakarta.

Margo, Mc. Caferry. 1999. Opioid and Pain Management. Journal of Nursing.

Martha, Davis. 1995. Panduan relaksasi dan reduksi stress. EGC, Jakarta.

Matteucci, Schub Tanja. 2010. Pain management: Dysmenorrhoea. Nursing Guide. Database: Nursing Reference Center. Cinanhl Sistem Informasi

Michelle, Larowe. 2011. About Lamaze Breathing Exercise. http://www.ehow.com/about 460 5970 lamaze-breathingexercises.html\#ixzz17UjiMIPZ. Diakses tanggal 1 Agustus 2015. 
Novia, Ika dan Nunik Puspitasari. 2008. Faktor resiko yang mempengaruhi kejadian disminore primer. The Indonesia Journal of Public Health. Vol. 4 No. 3.

Nursalam. 2008. Konsep dasar penerapan metodologi penelitian ilmu keperawatan pedoman skripsi, tesis dan instrument penelitian keperawatan. Salemba Medika, Jakarta.

O'Connell, K. Davis, A.R. dan Westhoff, C. 2006. Selftreatment patterns among adolescent girl with dysmenorrhea. Journal of pediatric and adolescent gynecology.

Ovedoff. 2002. Kapita Selekta Kedokteran. Alih Bahasa oleh Lyndon Saputra. Fakultas Kedokteran Universitas Trisakti, Jakarta.

Pallavi, M. et al. 2010. Clinical evidence dysmenorrhea. Page 813. Diakses tanggal 10 Agustus 2015.

Pract, Brjgen. 2009. The role of exercise in the treatment of menstrual disorders:the evidence.

Puji, Istiqomah. 2009. Keefektifan Senam Dismenore dalam Mengurangi Dismenore pada Remaja Putri di SMU N 5 Semarang.http://eprints.undip.id/ 9253/1/ARTIKEL_SKRIPSI234.p df.
Setiadi. 2007. Konsep dan penulisan riset keperawatan. Graha ilmu, Yogyakarta.

Singh, A., et al. 2008. Prevalence Ans Severity of Dysmenorrhea. A Problem Related to Menstruation, Among First and Second Year Female Medical Students. (online). Indian Journal Physiol Pharmaco. http://www.ncbi.nlm.nih.gov/pub med/1958 5756.

Smith, Roger $\mathrm{P}$, et al. 2012. Patien Information : painful menstrual periods(dysmenorrheal) (beyond the basic).

Sumantri, A. 2011. Metodologi penelitian kesehatan. Kencana Prenada Media Group. Edisi 1 cetakan 1, Jakarta.

Yustianingsih, A. 2004. Hubungan Aktifitas Olahraga Terhadap Disminorea Pada Siswi SMK Pemuda Muhammadiyah Krian Sidoarjo Jawa Timur. UGM, Yogjakarta.

${ }^{1}$ Dosen Akper Husada Jakarta 